\section{The entrepreneurial role in primary care dentistry}

\author{
S. Willcocks ${ }^{1}$
}

IN BRIEF
- Raises awareness of the new policy
context.
- Suggests this context will reinforce the
need to consider the business side of
dental practice.
- An entrepreneurial approach may be
required in order to sustain dental
practice in an increasingly competitive
environment.
- Provides a framework for exploring an
entrepreneurial approach in dental practice.

This paper explores the entrepreneurial role of dentists in primary care dentistry. It reviews the changing context of dentistry, not least the reforms being introduced by the health and social care bill. It suggests that this new context will reinforce the need to consider the business side of dental practice, in particular, the importance of quality, creativity and innovation, alongside the importance of meeting the needs of patients. An entrepreneurial approach will be required in order to sustain dental practice in an increasingly competitive environment.

An entrepreneurial role is increasingly important in primary care dentistry, given the policy shift towards quasi-markets, competition, new contracts, and patient choice. It is relevant regardless of whether it is in a private or NHS dental practice. The entrepreneurial role involves 'the process of initiating a business venture, organising the necessary resources and assuming the associated risks and rewards. ${ }^{1}$ In dentistry the process may involve, for example, the further development of the practice, a merger of practices, or the start-up of a new practice.

The individual entrepreneur is important in this process but it is difficult to identify a common set of personal qualities and behaviour associated with effectiveness in the role. It has been pointed out that 'very few entrepreneurs possess all the traits and attributes presented in the literature. ${ }^{2}$ However, there is still interest in personal characteristics, particularly in the form of competencies, which will be taken into account later in this paper. There is continuing interest in competency frameworks as a developmental and assessment tool in the health sector. The rationale for

'Lancashire Business School, University of Central Lancashire, Greenbank Building 263, Preston, PR1 2HE Correspondence to: Dr Steve Willcocks Email: SGWillcocks@uclan.ac.uk; Tel: 01772893410

\section{Refereed Paper}

Accepted 13 January 2012

DOI: 10.1038/sj.bdj.2012.177

${ }^{\bullet}$ British Dental Journal 2012; 212: 213-217 this is the importance of the link between competency and performance; 'the entrepreneur's demographic, psychological, and behavioural characteristics as well as their skills and technical know-how are often cited as the most influential factors to performance. ${ }^{2}$

The aim of this paper is to explore the relevance of entrepreneurship to dentists in the primary care sector in the UK.

\section{POLICY BACKGROUND}

The policy context of this paper is the primary dental care context in the UK. The government has embarked on a radical change programme for health services with the aim of creating 'the largest and most vibrant social enterprise sector in the world. ${ }^{3}$ However, the health sector is also targeted to reduce costs, increase productivity, eliminate waste, and maintain and improve quality. ${ }^{3}$ This brings with it considerable challenges and is likely to be the case for any healthcare system given the global nature of the recession.

Quality is highlighted in the UK government reforms alongside financial constraint. Dental practices will be expected to instigate quality improvements in clinical practice or in response to commissioning decisions or recommendations by the Care Quality Commission. The Department of Health (DOH) is piloting a new dental contract which is intended to enhance quality and patient experience, and introduce organisational accountability via a dental quality and outcomes framework. ${ }^{4}$ It has been argued that quality has been largely neglected in the existing dental contract. ${ }^{5}$ Since the Darzi report, ${ }^{6}$ leadership has been explicitly connected to quality, but this remains a challenge given the shift from process to outcomes as a measure of quality and the emphasis on competition as a spur to improving quality.

The reforms signal a major change to the structure of healthcare, in particular, existing health organisations will be phased out and new organisations will be introduced, creating a new devolved organisational landscape. However, it remains to be seen whether the government (indeed, any government) is able to remain at 'arm's length', given the pressures of the current national and international financial situation, and whether they, alongside the NHS Commissioning board and Care Quality Commission, will allow sufficient freedoms for entrepreneurial activity to flourish. The government has stated that they 'want to set dentists free from the burdens of targets and micromanagement that have turned what should be a rewarding career into a drill and fill treadmill'.4

The new structure is divided into two parts: a provider sector, which includes public and private hospitals and general dental and medical practices; and a commissioning sector. With regard to the latter, the government is introducing clinical led commissioning to replace existing primary care trusts. Commissioning groups will be 
given devolved budgetary responsibility for commissioning local health services and will be held to account by a new National Commissioning Board. However, the latter will be responsible for commissioning general medical and dental services. This addresses the issue of contestability and also creates the possibility of more integration across primary and hospital dental services. This might also have a negative effect in general terms in that the commissioning of primary and secondary care will be enacted by separate agencies.

In the above context, clinicians will be expected to develop the business objectives of their respective organisations. This is an area where dentists may be at an advantage, given their experience in running dental practices as a business. The role may include setting objectives or strategies relating to expansion and/or contraction, merger, or turnaround. For example, clinicians will be involved in 'identifying which services will be most effective and cost effective and planning both new investments and disinvestments, drawing on evidence and experience. ${ }^{8}$

It has been suggested that 'the changes could result in high performing [organisations] attempting to grow by attracting new patients or practices. It suggests a dynamic pseudo-market in commissioning. ${ }^{9}$ Dixon and Ham suggest that the government reforms may act as a stimulus to the motivation of clinicians to become involved in entrepreneurial activity. They are motivated by the opportunity to make or buy services in the context of a market opened up to any willing provider. ${ }^{10}$

\section{DEVELOPING THE ENTREPRENEUR- IAL ROLE IN DENTAL PRACTICE IN THE PRIMARY CARE SECTOR}

It is suggested that there are four key factors which may be related to the development of the entrepreneurial role for dentists: the characteristics of the individual entrepreneur, the operating sector, the processes and resources used by entrepreneurs and the mission and outcomes associated with the entrepreneur. ${ }^{2}$ These four factors will be utilised as a way of conceptualising the entrepreneurial role of the dentist in the primary care sector (Table 1).

Table 1 Factors related to the development of the entrepreneurial role for dentists to conceptualise their role in the primary care sector

\begin{tabular}{|c|c|c|c|}
\hline $\begin{array}{l}\text { Characteristics of the } \\
\text { clinical leader: dentist }\end{array}$ & $\begin{array}{l}\text { The operating sector: } \\
\text { primary care dentistry }\end{array}$ & $\begin{array}{l}\text { Processes and } \\
\text { resources }\end{array}$ & Mission/outcomes \\
\hline $\begin{array}{l}\text { Personal qualities } \\
\text { Knowledge } \\
\text { Skills } \\
\text { Entrepreneurial behaviour } \\
\text { Creativity } \\
\text { Values }\end{array}$ & $\begin{array}{l}\text { Structural and cultural } \\
\text { characteristics }\end{array}$ & $\begin{array}{l}\text { Business planning } \\
\text { Decision making } \\
\text { Marketing } \\
\text { Supporting } \\
\text { innovation } \\
\text { Obtaining resources }\end{array}$ & $\begin{array}{l}\text { Outcomes } \\
\text { framework } \\
\text { End results }\end{array}$ \\
\hline
\end{tabular}

\section{Characteristics of the dentist as entrepreneur}

There are many definitions of entrepreneurship and most definitions include individual characteristics/behaviours, in particular motivation, the ability to identify new opportunities and implement change, obtain resources and provide transformational leadership skills. ${ }^{11}$ Kirby provides a useful summary from the psychological literature of the personal characteristics of the entrepreneur, which include risk taking ability; a need for achievement; a belief that they themselves can make things happen; a desire for autonomy and fear of external control; a tendency towards 'deviant' behaviour; creativity and opportunism and intuition. ${ }^{12}$ Similarly, entrepreneurial attributes have been identified by Kempster and Cope as 'intellectual stimulation, ambitious foresight, creativity, a positive and decisive mind set, intuition, and unorthodox thinking.?

The latter is similar to the attributes required in transformational leadership, particularly intellectual stimulation. In terms of thinking (cognition) it has been said that entrepreneurs with a high need for cognition (NFC) are more effective at adaptive decision making. ${ }^{13}$ The latter is particularly important when the entrepreneur is operating in a fluid, rapidly changing, environment, such as the UK health system.

It can be argued that many of the above qualities are already in evidence in the dental profession, for example, a need for achievement and desire for autonomy, but more attention may be needed to be given to what Kirby describes as 'right side brain' qualities. These are required to facilitate creative thinking: 'right-brained thinking is lateral, unconventional, unsystematic and unstructured. It is this right-brained lateral thinking that is at the heart of the creative process. ${ }^{12}$
Dentists also need qualities/attributes which are supportive of clinical innovation and changing clinical practice. On the other hand, it has been suggested that in order to foster entrepreneurial learning there is a need to move from the emphasis on the cognitive abilities and thinking skills, towards an exploration of the emotional relationships between entrepreneur and the organisation. ${ }^{14}$ An emphasis on the emotional dimension is particularly relevant to healthcare and elsewhere, given the extent of organisational change.

\section{The operating sector: primary care dentistry}

It has been hypothesised that there are certain prerequisites that need to be in place to enable entrepreneurship to flourish, in particular, it is said that an unsettled environment is conducive to entrepreneurial activity: "entrepreneurship occurs in the public sector where there is an uncertain environment, a devolution of power, and at the same time, re-allocation of resource ownership, to unit management level. It is driven by individuals who have the ability to spot market opportunities and who are able through follower manipulation to act on them. ${ }^{15}$

It can be argued that the operating sector in primary care dentistry is in a state of flux at the beginning of a period of transformational change, involving considerable change to the status quo. It also meets the prerequisites of devolution and reallocation of resources. It has been suggested that the environment in which entrepreneurs operate is as important as entrepreneurial characteristics in defining the entrepreneurial process. ${ }^{15}$ Srivastava and Agrawal have identified common environmental factors supporting entrepreneurship such as rewards and motivation, management support, resource availability, organisational structure and risk taking. ${ }^{17}$ 
The availability of management support and showing concern for the well being of the individual have been identified as important in healthcare, particularly in terms of reducing levels of stress in the organisation. ${ }^{18}$

An overarching factor for all of these is the culture(s) of dental practice in primary care. It has been suggested that market-oriented organisations need an organisational culture that facilitates all activities involved with collecting data about customers and competitors in the target market and ensuring this is disseminated throughout the organisation. ${ }^{13}$ Along similar lines, the competing values approach to culture describes a developmental culture as a 'dynamic, entrepreneurial, and creative place to work. People are encouraged to take risks and to focus on innovation and individual initiative and freedom. The leaders are considered to be innovators and risk takers. Commitment to experimentation and innovation holds the organisation together. ${ }^{19}$

However, there are some problems with these environmental factors. With regard to rewards, motivation, and resource availability, these are severely constrained in healthcare generally by the current financial climate and threat to jobs, and, not least, by the threat to goodwill and psychological contract between staff and employers.

\section{Processes and resources}

These are an important source of leverage for entrepreneurial activity. The leverage is essentially about the process of innovation and change and techniques for dealing with it. For example, if one applies this to primary care dentistry, the dental practice may focus on the identification of a market niche, development of services appropriate to the chosen niche, idea generation, environmental scanning, recognising and taking advantage of opportunities and formulating strategies for taking advantage of opportunities. ${ }^{2}$

There is increasing scope in dental practices in the UK for prioritising market strategies within business plans, utilising techniques of market analysis, customer and competitor analysis, segmentation, application of the marketing mix and concepts associated with relationship marketing. ${ }^{20}$ Since 2008, NHS dentists have been encouraged to advertise and promote their services more widely. The new dental quality and outcomes framework will include the patient experience as part of its criteria of quality, such as assessing services against patient expectations and local needs. The UK government believe 'there needs to be more systematic and sophisticated approaches to profiling and understanding peoples needs and preferences, which will support all sections of the community to have a greater say in their health and care."

It is increasingly important that practices are outward-facing, adopt environmental scanning and forecasting techniques, and are able to identify market opportunities and customer needs, be they niche markets, or more main stream opportunities. In support of this, practices need to become more patient orientated and focused, rather than the historical emphasis on a professional led service. The UK government see this as the key to quality improvement in health services: 'only by putting people at the heart of their care and involving patients and their carers as much as they want to be in every decision about their care will the best outcomes be achieved'. ${ }^{3}$

With regard to resources, this remains the major challenge for the entrepreneur in dental practice, alongside productivity and improving patient outcomes. Within a tight government fiscal regime, the dental practice will have to operate on the assumption of limited resource growth, targets for efficiency savings and reductions in staffing costs. However, as stated above it can be argued that this context is a spur to entrepreneurial activity. Entrepreneurial practices will be required to obtain resources by other means such as income generation resulting from new ideas and clinical innovations, exploiting market opportunities and by competition for limited resources. This requires an enterprising and entrepreneurial organisation and entrepreneurial skills will be a source of competitive advantage $v i s-\dot{a}-v i s$ competitors in the dental sector.

\section{Mission/outomes}

Practices are required to pursue specific healthcare outcomes and a new outcomes framework is being introduced against which providers will be held to account. This represents an important part of the emphasis on improving quality in healthcare. The previous government introduced clinical governance as a system for dealing with variations in quality across the NHS. The emphasis was on the achievement of centrally determined targets. The government intends to shift the emphasis away from essentially process targets, towards the delivery of specified outcome targets, alongside greater emphasis on patient choice and the quality of the patient experience. ${ }^{21}$

This emphasis on outcomes as a measure of quality improvement fits well with definitions of entrepreneurship from a health sector perspective. Dakin et al. suggest that definitions of social entrepreneurship focus on 'the primary mission and outcomes of the social entrepreneur, which include creating social value by providing solutions to social problems. In contrast to the individual-level characteristics, processes, and activities, this approach focuses the definition of social entrepreneurship on the outcome of the efforts of the social entrepreneur. ${ }^{11}$

In this respect, practices may be required to change their mission and strategy. The latter is likely to be crucial in developing for a future uncertain environment. There is the possibility that providers who fail, or are adversely affected by competition, will not survive in the long term, certainly in their present form. The white paper states that the government will not provide additional resources for failing providers. ${ }^{3}$ It has been suggested that this represents a major challenge: 'accepting that providers who do not compete successfully may fail, resulting in a reduction in the publics access to services in some cases. ${ }^{10}$

\section{IMPLICATIONS FOR DENTAL PRACTICE}

There are various implications for dental practice that need to be addressed as a result of the above. At the individual level, it is acknowledged that dentists cannot be expected to take on an entrepreneurial role without adequate support, training and the right incentives. In healthcare, there is continuing interest in the competency approach as a way forward. If one assumes that competencies can be learned, there is a developmental issue for dentists. It has 
been suggested that 'both leadership and entrepreneurial competencies are more about how people behave and developing leadership and entrepreneurial competencies is about helping people to learn to behave in certain ways. ${ }^{2}$ It has been stated that the development of leadership competencies for clinical leaders on a strategic level is at a relatively early stage.

This is complicated by the fact that there is a lack of agreement about entrepreneurship generally, and skills/competencies in particular. Mitchelmore and Rowley have shown that different authors have identified different characteristics, such as personal background and experience, educational attainment, intellectual abilities, social abilities, personality and behavioural characteristics. ${ }^{2}$

Given this diversity, a case can be made for a contingency model of competency, wherein entrepreneurial competencies are identified in terms of how well suited and appropriate they are for particular contexts, in this case, the primary care dental context. Competencies may be determined by the organisational life cycle; whether it is about starting up a new organisation, or developing an existing organisation. With regard to the former, it has been suggested that different skills are required for different stages in the growth of a new organisation with start up, survival, success and take off, a period of rapid growth and resource maturity. ${ }^{1}$

Alternatively, if one applies a distributed leadership perspective, entrepreneurship in dental practice may be conceptualised as a shared activity, rather than the domain of the individual dentist. This may be particularly suited to larger practices where the entrepreneurial or leadership role cannot be undertaken effectively by one individual. A shared or distributed perspective also takes account of the value of multidisciplinary dental teams in the entrepreneurial process.

Another implication is the emphasis on shifting the orientation of dental practice towards its customers or patients, in particular, ensuring a customer focus and utilising methods, techniques and resources appropriate to this focus. The latter may include those available from within the marketing discipline such as marketing strategy, marketing mix, and relationship marketing. These are potentially perceived as alien to the health sector, so there is a need to ensure that they are shown to be relevant.

The changes will require a shift in the mindsets of those involved, enabling them to move closer to an entrepreneurial mindset and associated values. However, in recent years there has been a problem of clinical engagement, in other words, the extent to which clinicians have supported or opposed various healthcare reforms. The UK government believe that 'a cultural change is needed, which should be brought about through leadership and action across the health community. ${ }^{3}$ In dental practice it is not just the culture of the dental profession but the wider dental team.

There is also the importance of providing an underpinning strategic direction or logic alongside the need to consider a change in mission for the practice to facilitate a more entrepreneurial approach. Given the scale and magnitude of the changes in healthcare, particularly increasing competition and greater patient involvement, there is a need to be flexible and innovative in developing new practices and in transforming relatively mature, existing practices. A flexible strategy is important, one that embraces the inter-relationships and collaborative nature of dental healthcare delivery.

A particular challenge will be how to sustain the competitive advantage of the practice in the context of financial constraint and increasing competition, for example, from the private dental companies. The entrepreneurial role is to provide a spur to organisational change, with the entrepreneur involved in challenging the 'status quo and may thus be regarded as a change agent.' ${ }^{12}$

A more general issue is the extent to which primary care dentistry is receptive or conducive to entrepreneurial activity. This has implications for the cultural change required to facilitate a new approach, the pace of change, the presence or otherwise of barriers to entrepreneurship such as professional resistance, and the effectiveness of incentives put in place by government policy. It has been suggested that 'the biggest challenge is the pace of systemic and organisational change..22 The process of making such wide-ranging organisational changes will take time and cannot be fast tracked without implications, such as the possibility of change fatigue or burnout. The process of developing new and existing organisations will have an impact on structural, emotional and cultural dimensions, including a potential change of values.

\section{CONCLUSION}

This paper has explored the role of the entrepreneur in the context of dental practice in the UK. It has been suggested that 'in the increasingly turbulent and competitive environment business firms face today, a type of entrepreneurial leader distinct from other behavioural forms of leadership is required'?

This environment is also an important influence in the dental sector. It is suggested that the type of entrepreneurial leader needed in primary care dentistry may be conceptualised along four dimensions: individual entrepreneurial characteristics; nature of the operating sector; processes and resources used by entrepreneurs; and the mission and outcomes associated with the entrepreneur. ${ }^{2}$

This suggests that there are a combination of different factors contributing to the effectiveness of entrepreneurs in dental practice, ranging from individual characteristics, such as competencies and the creative process, to the influence of the environment and factors concerning mission and strategy. Given this diversity, it is suggested that the entrepreneurial role may be a contingency specific role, depending on the context. In other words, there is no one right way to conceptualise the role.

The implications of these suggestions are briefly discussed. This points to the need to embrace a relatively eclectic approach to developing entrepreneurship in dental practice. It is particularly important to ensure that the cultural implications are fully addressed given the extent of organisational change envisaged in the reform programme.

1. Daft R L, Kendrick M, Vershinina N. Management. Hampshire: South-Western Cengage Learning, 2010

2. Mitchelmore S, Rowley J. Entrepreneurial competencies: a literature review and development agenda. Int J Entrepreneurial Behav Res 2010; 16: 92-111.

3. Department of Health. Equity and excellence: liberating the NHS. London: Department of Health, 2010.

4. Department of Health. NHS dental contract: proposals for pilots. London: Department of Health, 2010. 
5. Mills I, Batchelor P. Quality indicators: the rationale behind their use in NHS dentistry. Br Dent J 2011 211: 11-156.

6. Department of Health. High quality care for all: NHS next stage review final report. London: Department of Health, 2008

7. Kempster S, Cope J. Learning to lead in the entrepreneurial context. Int J Entrepreneurial Behav Res 2010; 16: 5-34

8. Department of Health. The functions of GP com missioning consortia: a working document. London: Department of Health, 2011.

9. Hakin B. Putting half truths and confusions to the sword. Health Serv J 2011: 121: 14-15.

10. Dixon A, Ham C. Liberating the NHS: the right prescription in a cold climate? The King's Fund, 2010.

11. Dacin P A, Dacin M T, Matear M. Social entrepreneurship: why we don't need a new theory and how we move forward from here. AMP 2010; 24: $37-57$
12. Kirby D A. Entrepreneurship education: can business schools meet the challenge? In Genesca $E_{\text {, }}$ Urbano D, Capelleras J L, Guallarte C, Verges J (eds) Entrepreneurship: homage to Professor J M Veciana Verges. Barcelona: Universitat Autonoma de Barcelona, 2003

13. Zhang D D, Bruning E. Personal characteristics and strategic orientation: entrepreneurs in Canadian manufacturing companies. Int J Entrepreneurial Behav Res 2011, 17: 82-103.

14. Tracey P, Phillips N. The distinctive challenge of educating social entrepreneurs: a postscript and rejoinder to the special issue on entrepreneurship education. Acad Manag Learn Edu 2007; 6: 264-271.

15. Boyett I. The public sector entrepreneur: a definition. Int J Entrepreneurial Behav Res 1997; 3: 77-92.

16. Matlay H. Entrepreneurship education in UK business schools: conceptual, contextual and policy considerations. J Small Bus Enterprise Dev 2005; 12: 627-643.

17. Srivastava N, Agrawal A. Factors supporting corporate entrepreneurship: an exploratory study. VISION - J Business Perspective 2010; 14: 163-171.

18. Alimo-Metcalfe B, Alban-Metcalfe J. The myth and morality of leadership in the NHS. Clinician Management 2004; 12: 49-53.

19. San Park J, Hyun Kim T. Do types of organizational culture matter in nurse job satisfaction and turnover intention? Leadership Health Services 2009; 22 $120-38$.

20. Willcocks S. Clinical leadership in UK healthcare: exploring a marketing perspective. Leadership Health Services 2008; 21: 158-167.

21. Nuffield Trust. The Coalition government's NHS reforms: an assessment of the white paper. London: Nuffield Trust, 2010.

22. Hartley J, Benington J. Leadership for healthcare. Bristol: Policy Press, 2010 